JOURNAL OF MECHANICAL ENGINEERING, MANUFACTURES, MATERIALS AND ENERGY

Doi: $10.31289 /$ jmemme.v5i2.5405

Available online http://ojs.uma.ac.id/index.php/jmemme

\title{
Pengaruh Diameter Knee pada Head Loss Aliran Berbasis Monogram, CAD dan CAE
}

\section{Effect of Knee Diameter on Head Loss Flow Based on Monogram, CAD and $C A E$}

\author{
Nur Hayati1)*, Adi Purwanto2), Erwan Muladi3) \\ 1,2,3 IST Akprind Yogyakarta \\ Diterima: 21-06-2021 ; Disetujui: 13-09-2021 ; Diterbitkan: 30-12-2021 \\ *Corresponding author: E-mail: nurhayati@akprind.ac.id
}

\begin{abstract}
Abstrak
Pipa digunakan sebagai alat transportasi fluida dari suatu penampungan ke tempat tujuan. Di dalam suatu sistem perpipaan selalu ditemukan rugi aliran atau headloss, baik headloss akibat ukuran pipa maupun headloss akibat adanya belokan, salah satunya knee. Tujuan penelitian ini adalah mengetahui pengaruh diameter knee terhadap headloss aliran. Metode yang digunakan simulasi dan perhitungan monogram. Berdasarkan standar ASME B16.9 B16.28 digunakan knee dengan diameter 1, 2, 4 dan inch. Hasil eksperimen menunjukkan perilaku yang sama antara simulasi dengan perhitungan monogram. Semakin besar diameter knee, maka headloss semakin kecil. Headloss hasil simulasi berturut-turut untuk diameter knee 1,2,4 dan 6 inch masing-masing 0,012 m, 0,0093 m, 0,00063 $\mathrm{m}$ dan 0,00426 $\mathrm{m}$. Sedangkan headloss hasil perhitungan monogram masing-masing 0,006 $\mathrm{m}, 0,0024 \mathrm{~m}$, $0,0007 \mathrm{~m}$ dan $0,004 \mathrm{~m}$. Headloss terkecil terjadi pada diameter 4 inch mengindikasikan bahwa knee dengan diameter ini adalah knee terbaik diantara keempat knee lainnya.
\end{abstract}

Kata Kunci: CAD; headloss; knee; monogram

\begin{abstract}
Pipes are used as a means of fluid transportation from a reservoir to a destination. In a piping system, flow loss or head loss is always found, both head loss due to pipe size and head loss due to bends, one of which is the knee. The purpose of this study was to determine the effect of knee diameter on flow headloss. The method used is simulation and monogram calculation. Based on the standard ASME B16.9 B16.28 used knees with a diameter of 1, 2, 4 and inch. The experimental results show the same behavior between the simulation and the monogram calculation. The larger the knee diameter, the smaller the head loss. Headloss simulation results for knee diameters 1,2,4 and 6 inches are $0,012 \mathrm{~m}, 0,0093 \mathrm{~m}, 0,00063 \mathrm{~m}$ and 0,00426 $\mathrm{m}$, respectively. Meanwhile, the headloss calculated by the monogram is $0.006 \mathrm{~m}, 0.0024 \mathrm{~m}, 0.0007 \mathrm{~m}$ and $0.004 \mathrm{~m}$, respectively. The smallest headloss occurred at 4 inches in diameter indicating that the knee with this diameter is the best knee among the other four knees.
\end{abstract}

Keywords: CAD; headloss; knee; monogram

How to Cite: Hayati, N., 2021, Pengaruh Diameter Knee pada Head Loss Aliran Berbasis Monogram, CAD dan CAE, JMEMME (Journal of Mechanical Engineering, Manufactures, Materials and Energy), 5 (02): 194-201. 


\section{PENDAHULUAN}

Air merupakan kebutuhan vital setiap makhluk hidup untuk keperluan minum, sanitasi dan lain sebagainya. Berbagai upaya dilakukan agar dapat mengalirkan air dari sumber air ke tempat tujuan. Salah satunya dengan merangkai sistem pipa untuk mengalirkan air ke tempat tujuan. Di dalam sistem perpipaan diperlukan suatu sambungan ataupun belokan. Sambungan dapat berupa knee, elbow maupun mitter Di dalam proses pendistribusian air, sering terjadi kehilangan energi yaitu terjadinya head losses pada sambungan dan belokan $[1,2,3,4,5]$. Adanya headloss mengakibatkan penurunan tekanan.

Fuida

Fluida adalah zat yang dapat mengalir dan mempunyai partikel yang mudah bergerak [6]. Fluida mempunyai ketahanan bentuk yang sangat kecil sehingga mudah mengikuti bentuk ruang. Fluida yang mengalir sangat tergantung dengan kecepatan rata-rata aliran dalam pipa yang dihitung menggunakan persamaan (1).

$$
Q=A \cdot v
$$

dimana $Q=$ debit aliran fluida $\left(\mathrm{m}^{3} / \mathrm{s}\right), \mathrm{A}=$ diameter knee $(\mathrm{m}), v=$ kecepatan fluida $(\mathrm{m} / \mathrm{s})$

\section{Head Losses}

Head loss adalah rugi-rugi aliran. Menurut Priyati dkk (2019) dan Putra dkk (2017) head loss terdiri dari dua macam, yaitu head loss mayor dan head loss minor [7, 8]. Penjumlahan dari headloss mayor dan headloss minor merupakan head loss total.

a) Head Loss Mayor

Head loss mayor terjadi karena adanya gesekan antara aliran fluida yang mengalir dengan dinding permukaan dalam pipa. Pada umumnya head loss ini dipengaruhi oleh panjang pipa. Perhitungan head loss mayor menurut Darcy Weisbach dapat dilakukan dengan menggunakan persamaan (2).

$$
H_{f}=f \frac{L v^{2}}{D 2 g}
$$

dimana $H_{f}=$ head loss mayor $(\mathrm{m}), f=$ faktor gesekan (dapat diketahui melalui diagram Moody), $L=$ panjang pipa (m), $D=$ diameter pipa (m), $v=$ kecepatan aliran (m/s), dan $g=$ percepatan gravitasi $\left(\mathrm{m} / \mathrm{s}^{2}\right)$.

\section{Head Loss Minor}

Head loss minor terjadi karena adanya sambungan pipa (fittings) seperti pada belokan pipa, yaitu knee, elbow, dan mitter. Head loss minor dapat dihitung dengan menggunakan persamaan (3).

$$
H_{m}=k \frac{v^{2}}{2 g}
$$


dimana $v=$ kecepatan fluida (m/s), $k=$ koefisien minor losses, dan $g=$ percepatan gravitasi $\left(\mathrm{m} / \mathrm{s}^{2}\right)$.

Monogram

Monogram digunakan untuk mengetahui karakteristik aliran fluida yang disediakan dari beberapa data dalam bentuk tabel. Selain itu, monogram dikembangkan berdasarkan rumus Hazen-Williams dengan "faktor C 130" untuk menyediakan kapasitas aliran (gpm), kerugian gesekan (ft of H2O/100 ft) dan kecepatan aliran (ft/s) untuk produk pipa bertekanan.

\section{CAD dan CAE}

Penggunaan teknologi CAD (Computer Aided Design) dan CAE (Computer Aided Engineering) dimanfaatkan dalam proses desain dan simulasi yaitu SolidWorks 2016. Di dalam SolidWorks ini disediakan fitur based parametric solid modeling sehingga memudahkan dalam proses simulasi. Dengan software dilakukan meshing (pembagian ruang) pada setiap titik kontrol dengan batasan domain dan boundary condition yang telah ditentukan $[9,10,11,12]$.

\section{METODE PENELITIAN}

Metode yang digunakan pada penelitian ini adalah metode simulasi dan perhitungan monogram. Berdasarkan standar ASME B16.9 B16.28 digunakan knee dengan diameter 1, 2, 4 dan inch sebagai variabel bebas. Sedangkan variabel terikatnya adalah headloss pada knee. Knee merupakan sambungan dua pipa dengan sudut radius pendek [13]. Dimensi dari knee diperlihatkan pada Tabel 1. Sketsa knee berdasarkan variasi diameter diperlihatkan pada gambar 1 . Proses simulasi menggunakan software Ansys Workbench 19.0. Data yang digunakan pada pengujian knee diperlihatkan pada tabel 2.

Tabel 1. Dimensi Standar Knee

\begin{tabular}{cccc}
\hline $\begin{array}{c}\text { Nominal Pipe Size } \\
\text { (NPS) }\end{array}$ & $\begin{array}{c}\text { Outside Diameter } \\
\text { (OD) }\end{array}$ & Radius (A) & $\begin{array}{c}\text { Wall Thickness (Sch } \\
80 \mathrm{~S} \text { ) }\end{array}$ \\
\hline 1" & $33,4 \mathrm{~mm}$ & $38,1 \mathrm{~mm}$ & $4,5 \mathrm{~mm}$ \\
2" & $60,3 \mathrm{~mm}$ & $76,2 \mathrm{~mm}$ & $5,5 \mathrm{~mm}$ \\
$4 "$ & $114,3 \mathrm{~mm}$ & $152,4 \mathrm{~mm}$ & $8,6 \mathrm{~mm}$ \\
6" & $168,3 \mathrm{~mm}$ & $228,6 \mathrm{~mm}$ & $11,0 \mathrm{~mm}$ \\
\hline
\end{tabular}




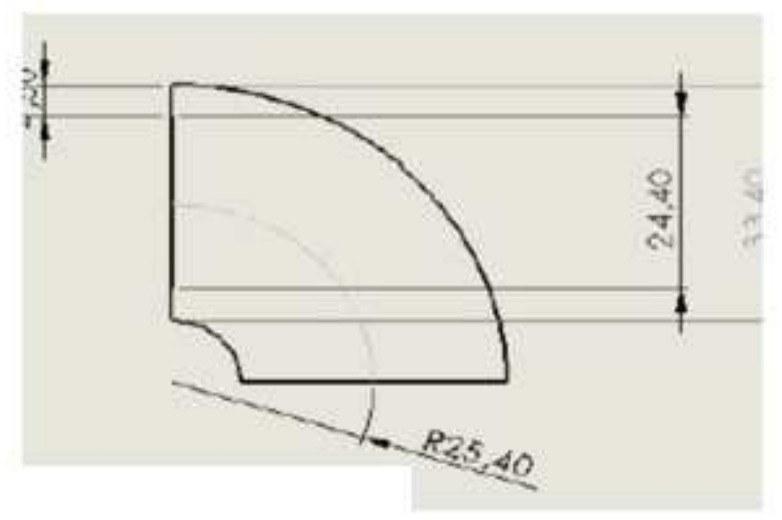

(a)

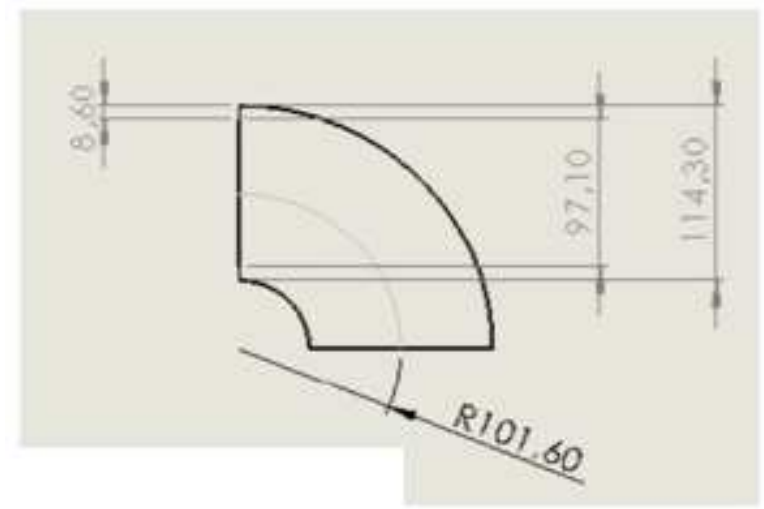

(c)

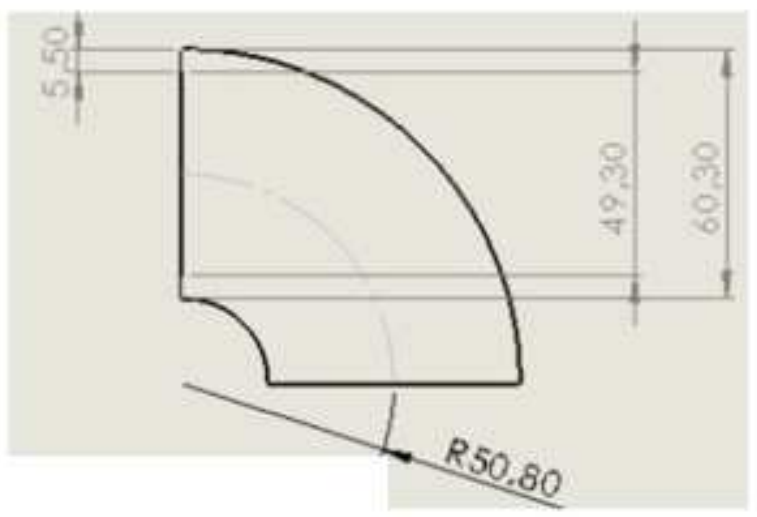

(b)

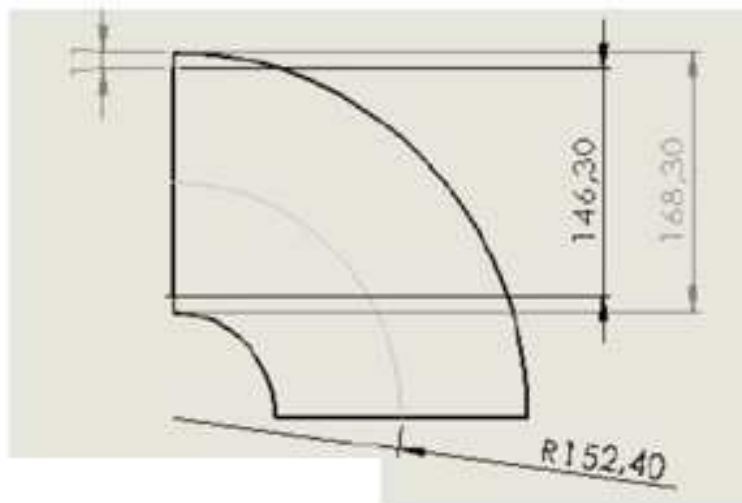

(d)

Gambar 1. Sketsa knee: (a) 1 inci, (b) 2 inci, (c) 4 inci, dan (d) 6 inci

Tabel 2. Spesifikasi material dan fluida pengujian

\begin{tabular}{|c|c|}
\hline \multicolumn{2}{|c|}{ Material fittings } \\
\hline Bahan & Stainless steel \\
\hline Model type & Linear Elastic Isotropic \\
\hline Yield strength & $172.339 \mathrm{~N} / \mathrm{mm} 2$ \\
\hline Tensile strength & $513.613 \mathrm{~N} / \mathrm{mm}^{2}$ \\
\hline Elastic modulus & $200000 \mathrm{~N} / \mathrm{mm}^{2}$ \\
\hline Poisson's ratio & 0.28 \\
\hline Mass density & $7800 \mathrm{~kg} / \mathrm{m} 3$ \\
\hline Shear modulus & $78000 \mathrm{~N} / \mathrm{mm}^{2}$ \\
\hline \multicolumn{2}{|c|}{ Fluida yang digunakan } \\
\hline Density & $998.2 \mathrm{~kg} / \mathrm{m} 3$ \\
\hline Cp (specific heat) & $4182 \mathrm{j} / \mathrm{kg}-\mathrm{k}$ \\
\hline Termal conductivity & $0.6 \mathrm{w} / \mathrm{m}-\mathrm{k}$ \\
\hline Viscousity & $0.001003 \mathrm{~kg} / \mathrm{m}-\mathrm{s}$ \\
\hline
\end{tabular}




\section{HASIL DAN PEMBAHASAN}

Simulasi pengujian kecepatan aliran pada knee menggunakan software Ansys Workbench 19.0. Hasil simulasi pengujian terebut diperlihatkan pad a gambar 2.

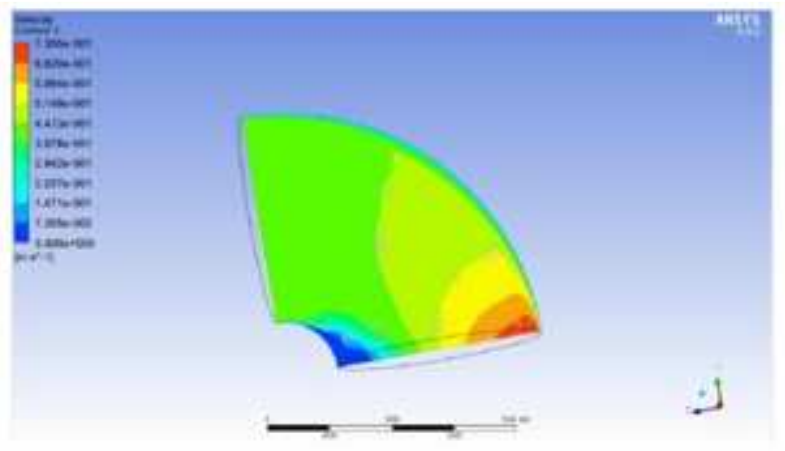

(a)

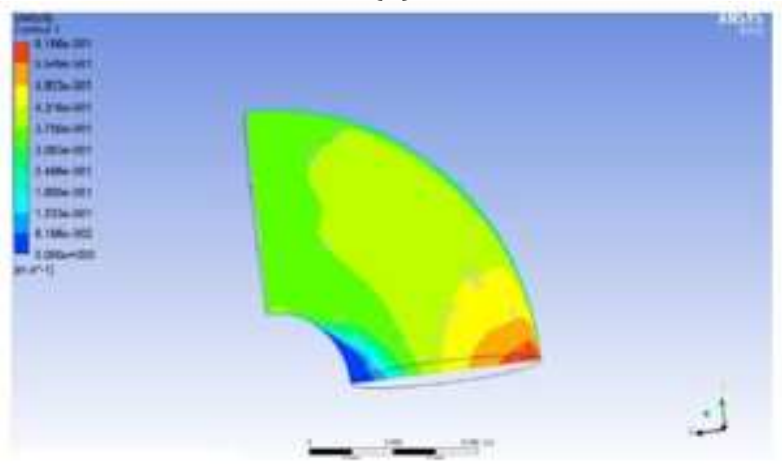

(c)

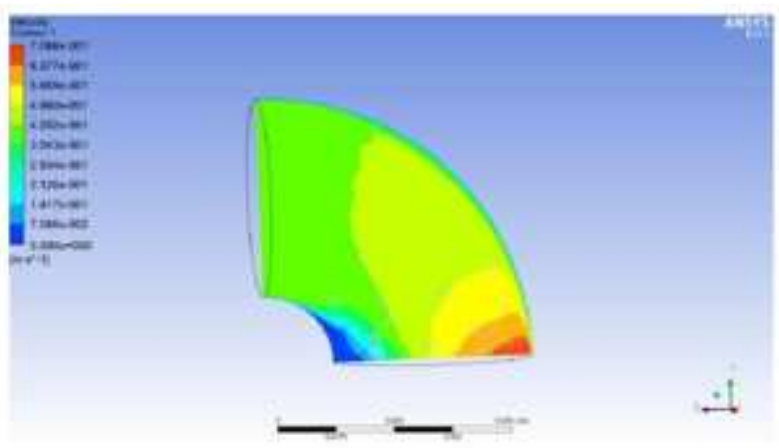

(b)

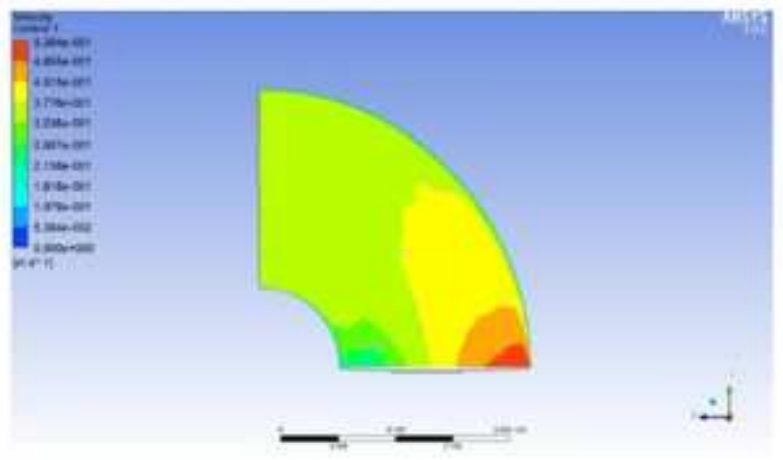

(d)

Gambar 2. Hasil Simulasi Knee: (a) 1 inci, (b) 2 inci, (c) 4 inci, dan (d) 6 inci

Warna-warna pada knee menunjukkan distribusi kecepatan aliran yang melewati knee pada masing-masing diameter 1, 2, 4 dan 6 inch. Warna merah menunjukkan kecepatan terbesar dari aliran. Sedangkan warna biru menunjukkan kecepatan terkecil dari aliran. Dari data tersebut diperoleh data debit aliran dan headloss dengan variasi diameter knee. Debit aliran dan headloss dengan variasi diameter knee diperlihatkan pada tabel 3. Pengaruh debit aliran terhadap diameter knee ditunjukkan pada gambar 3.

Tabel 3. Data Debit Aliran dan Headloss dengan Variasi Diameter Knee

\begin{tabular}{clll}
\hline Nama & \multicolumn{1}{c}{$\begin{array}{c}\text { Debit aliran } \\
\left(\mathrm{m}^{3} / \mathrm{s}\right)\end{array}$} & \multicolumn{1}{c}{$\begin{array}{c}\text { Headloss hasil simulasi } \\
(\mathrm{m})\end{array}$} & $\begin{array}{c}\text { Headloss perhitungan } \\
\text { monogram }(\mathrm{m})\end{array}$ \\
\hline Knee 1 inch & 0,0000297 & 0,012 & 0,006 \\
Knee 2 inch & 0,00113 & 0,0093 & 0,0024 \\
Knee 4 inch & 0,00398 & 0,00063 & 0,0007 \\
Knee 6 inch & 0,00775 & 0,00426 & 0,004 \\
\hline
\end{tabular}




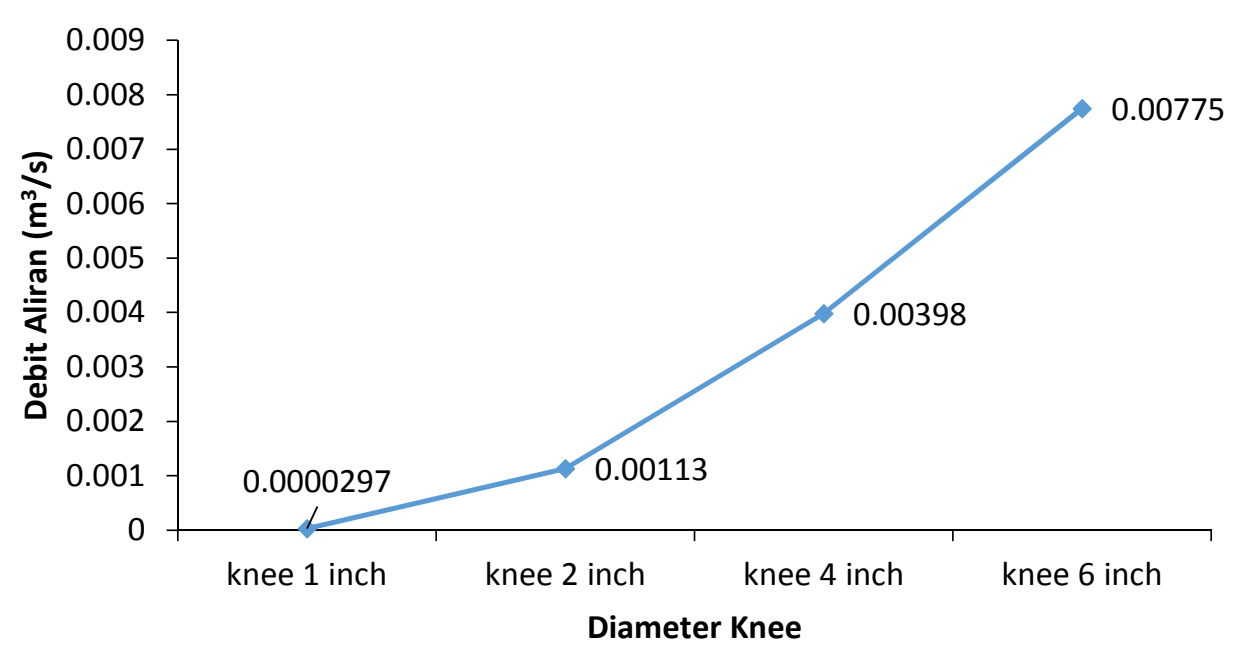

Gambar 3. Grafik debit aliran vs diameter knee

Pada gambar di atas terlihat bahwa debit aliran mengalami kenaikan seiring dengan bertambahnya diameter knee. Semakin besar diameter knee yang digunakan maka debit aliran yang mengalir juga semakin besar.

Pengaruh diameter knee terhadap headloss ditunjukkan pada gambar 4. Pada grafik tersebut terlihat ada perbedaan nilai headloss ketika suatu fluida melewati sebuah knee. Headloss cenderung mengalami penurunan seiring bertambahnya diameter knee. Headloss terkecil dicapai pada diameter knee 4 inch dan kembali meningkat tajam pada diameter knee 6 inch.

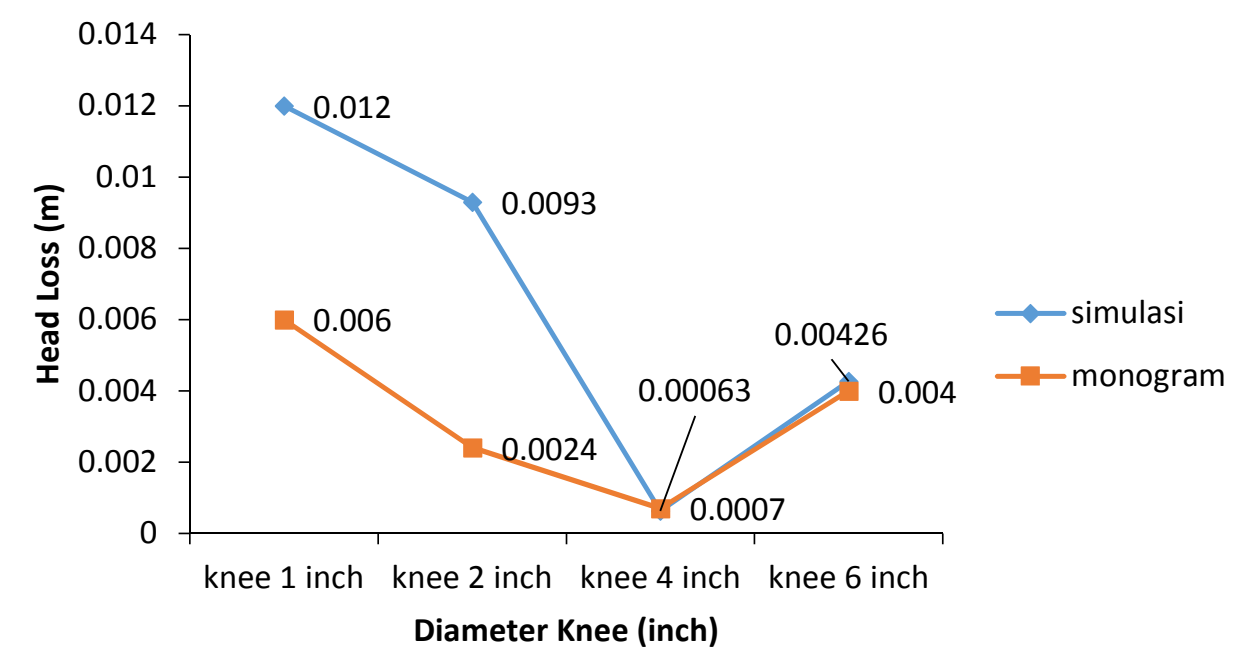

Gambar 4. Grafik headloss vs diameter knee

Aliran fluida yang mengalir melalui belokan menyebabkan terjadinya separasi [14]. Adanya separasi ini menyebabkan pemisahan aliran dan turbelensi. Losses semakin bertambah seiring dengan bertambahnya sudut belokan. Pada saat itu muncul gaya sentrifugal yang bekerja pada partikel-partikel fluida. Besarnya gaya sentrifugal sebanding dengan kuadrat kecepatan fluida. Kecepatan fluida ketika melewati belokan 
tidak seragam yaitu semakin besar ketika menjauhi pusat. Akibatnya gaya sentrifugal yang bekerja pada dinding jauh lebih besar dibandingkan gaya sentrifugal pada bagian pusat belokan sehingga timbul aliran sekunder $[15,16,17]$. Akibatnya losses pada knee dengan diameter besar kembali meningkat.

Kualitas pipa dan fitting kecuali di tentukan berdasarkan kualitas fisik berupa tampilan warna, dimensi, sistim koneksi (ulir atau flange) dan lain sebagainya ditentukan pula oleh head losses apabila dialirifluida. Semakin besar head losses semakin berkurang kualitas pipa dan fitting tersebut. Kualitas fisik dapat mudah dikenali oleh konsumen, namun head losses harus dilakukan penelitian laboratoris [18]. Berdasarkan data di atas, dapat disimpulkan bahwa knee dengan diameter 4 inch adalah knee terbaik karena memberikan nilai headloss terkecil dibandingkan ketiga knee yang lain.

\section{KESIMPULAN}

Berdasarkan hasil eksperimen, diperoleh losses terbesar terjadi pada knee dengan diameter 1 inch sedangkan losses terkecil pada diameter knee 4 inch. Simulasi dan perhitungan monogram menunjukkan hasil yang sama.

\section{UCAPAN TERIMA KASIH}

Terima kasih kami ucapkan kepada pihak jurusan Teknik Mesin IST Akprind Yogyakarta yang telah mendukung sepenuhnya penelitian ini.

\section{REFERENSI}

[1] Z. Zainudin, "Analisa Pengaruh Variasi Sudut Sambungan Belokan Terhadap Head Losses Aliran Pipa," Dinamika Teknik Mesin, pp. 34-45, 2012.

[2] W. Negara, "Perbandingan Analisis Pressure Drop pada Pipa Lengkung 90 ${ }^{\circ}$ Standar ANSI B36.10 dengan Cosmosfloworks 2007," Jurnal Teknik Mesin Universitas Gunadharma, vol. 2, no. 1, pp. 20-33, 2011.

[3] I. Putra, "Analisa Rugi Aliran (Head Losses) pada Pipa PVC," in Seminar Nasional Peranan Ipteks Menuju Industri Masa Depan, Jakarta, 2017.

[4] N. Salam, "Pengaruh Potongan Pipa pada Pipa Miter $90^{\circ}$ terhadap Kerugian Head Aliran Fluida," Jurnal Energi dan Manufaktur, vol. 8, no. 2, pp. 45-53, 2015.

[5] W. Fathoni and S. Novianto, "Analisa Aliran Fluida (Fully Develop Flow) pada Pipa Circular dengan Menggunakan CFD Fluent," Jurnal Teknik Mesin Untirta, vol. 4, no. 2, pp. 78-86, 2018.

[6] A. Arijanto, Y. Eflita and F. T. Sinaga, "Analisis Pengaruh Kekentalan Fluida Air dan Minyak Kelapa pada Performansi Pompa Sentrifugal," Jurnal Teknik Mesin, vol. 3, no. 2, pp. 78-89, 2015.

[7] A. Priyati, S. H. Abdullah and K. Hafiz, "Analisis Head Losses Akibat Belokan Pipa 90 (Sambungan Vertikal) dengan Pemasangan Tube Bundle," Jurnal Ilmiah Rekayasa Pertanian dan Biosistem, vol. 7, no. 1, pp. 112-123, 2019.

[8] E. Putra, I. Ismet, S. Sulaiman and A. Galsha, "Analisa Rugi Aliran (Head Losses) pada Belokan Pipa PVC," in Seminar Nasional Peranan Ipteks Menuju Industri Masa Depan, Padang, 2017.

[9] J. Jalaluddin, S. Akmal, N. Za and I. Ishak, "Analisa Profil Aliran Fluida Cair dan Pressure Drop pada Pipa L menggunakan Metode Simulasi Computational Fluid Dynamic (CFD)," Jurnal Teknologi Kimia Unimal, vol. 8, no. 1, pp. 42-56, 2019. 
[10] A. Sofyan, J. Glusevic, A. J. Zulfikar and B. Umroh, "Analisis Kekuatan Struktur Rangka Mesin Pengering Bawang," JMEMME (Journal of Mechanical Engineering Manufactures Materials and Energy), vol. 3, no. 1, pp. 20-28, 2019.

[11] A. J. Zulfikar and M. Y. R. Siahaan, "Analisis Signifikansi Roda Skateboard Berbahan Komposit Serbuk Batang Pisang Terhadap Perfoma Kecepatan Dengan Metode Anova," Jurnal Rekayasa Material, Manufaktur dan Energi, vol. 4, no. 2, pp. 83-9o, 2021.

[12] A. J. Zulfikar, A. Sofyan and M. Y. Siahaan, "Numerical Simulation on The Onion Dryer Frame Capacity of $5 \mathrm{~kg} /$ hour," JMEMME (Journal of Mechanical Engineering Manufactures Materials and Energy), vol. 2, no. 2, p. 86-92, 2018.

[13] B. Benkan, Benkan Pipe Fittings, Tokyo: Benkan Kikoh Corporation, 2016.

[14] S. Wahyudi and P. Pratikto, "Penurunan Kerugian Head Pada Belokan Pipa Dengan Peletakan Tube bundle," Jurnal Teknik Mesin, vol. 12, no. 1, pp. 44-56, 2010.

[15] A. Fahruddin and M. Mulyadi, "Rancang Bangun Alat Uji Head Losses dengan Variasi Debit dan Jarak Elbow 900 untuk Sistem perpipaan yang Efisien," Jurnal Teknik Mesin, vol. 5, no. 1, pp. 33-45, 2018.

[16] D. Y. Kurniawan, S. Sumarji and F. Kristianta, "Simulasi Perancangan Saluran Tuang Pada Pembuatan Pipe Reducer $\varnothing$ 12" Ke $\varnothing$ 10" FC25 Dengan Perangkat Lunak Solidcast," Unej Journal, vol. 2, no. 2, pp. 1-5, 2014.

[17] E. Eswanto and D. Syahputra, "Analisa Distribusi Kapasitas Aliran Fluida di Daerah Percbangan pada Sistem Perpipaan," Jurnal Teknologi Terapan, vol. 3, no. 1, pp. 12-20, 2017.

[18] M. F. Ilham, J. Jusafwar and A. Syuriadi, "ANALISA HEAD LOSSES PADA CIRCULATING WATER PIPE LINE PLTGU PERAK GRATI," in Seminar Nasional Teknik Mesin, Jakarta, 2018. 